\title{
Dual antiplatelet therapy in patients with coronary artery disease after percutaneous coronary intervention with drug-eluting stents: A systematic review and network meta-analysis
}

Yi Xu

Zhejiang University School of Medicine Second Affiliated Hospital

\section{Yimin Shen}

Zhejiang University School of Medicine Second Affiliated Hospital

Pengfei Zhao

Shanghai Institute of Materia Medica Chinese Academy of Sciences

Yuanyuan Han

ChniacoHealthcare Corporation International Hospital

Jun Jiang ( $\nabla$ jiang-jun@zju.edu.cn )

Zhejiang University School of Medicine Second Affiliated Hospital https://orcid.org/0000-0001-69269516

Research article

Keywords: Dual antiplatelet therapy, Coronary artery disease, Percutaneous coronary intervention, Drugeluting stent, $\mathrm{P} 2 \mathrm{Y} 12$ receptor inhibitor

Posted Date: October 29th, 2020

DOI: https://doi.org/10.21203/rs.3.rs-97427/v1

License: (c) (i) This work is licensed under a Creative Commons Attribution 4.0 International License. Read Full License 


\section{Abstract}

Background: This network meta-analysis was committed to evaluating the efficacy and safety of different dual antiplatelet therapies (DAPTs) after percutaneous coronary intervention (PCl) with drugeluting stents (DESs).

Methods: Randomized controlled trials (RCTs) comparing two of the following DAPT strategies: long-term (>12 months) DAPT (L-DAPT), 12-months DAPT (DAPT 12Mo), short-term ( $\leq 6$ months) DAPT followed by aspirin monotherapy (S-DAPT+ASA), short-term DAPT followed by a P2Y12 receptor inhibitor monotherapy (S-DAPT+P2Y12) were searched. Primary outcomes were all-cause mortality, cardiac death, myocardial infarction (MI), stroke, major bleeding, any bleeding, definite or probable stent thrombosis (ST). This Bayesian network meta-analysis was performed with the random-effects model.

Results: Twenty-four RCTs $(n=81,376)$ were included. L-DAPT increased the risk of major bleeding (OR $2.37,95 \% \mathrm{Cl} 1.32-5.03$ compared with S-DAPT+P2Y12) and any bleeding (OR 2.95, 95\% Cl 1.91-4.34 compared with S-DAPT+P2Y12). When compared with L-DAPT, DAPT 12Mo (OR 1.54, 95\%Cl 1.13-2.02) and DAPT+ASA (OR 1.67, 95\% Cl 1.22-2.19) were associated with higher rates of MI, but S-DAPT+P2Y12 obtained no statistical difference. The sensitivity analysis revealed that the risks of major bleeding and any bleeding further increased for $\geq 18$ months of DAPT. In the subgroup analysis, short-term DAPT (SDAPT) presented similar efficacy and safety to DAPT 12Mo for patients with the acute coronary syndrome (ACS), and lower risks of major bleeding and all-cause mortality were observed in SDAPT+P2Y12 among patients with newer-generation DES.

Conclusions: S-DAPT+P2Y12 presented superiority in patients with all clinical presentations, for a lower risk of bleeding and not associated with increased ischemic harm. Besides, prospective research between aspirin monotherapy and P2Y12 monotherapy was required.

\section{Background:}

DAPT represented by a combination of aspirin and a P2Y12 receptor inhibitor is widely admired among patients with coronary artery disease (CAD) undergoing PCI with DESs [1, 2]. Nevertheless, optimal DAPT strategies remain further exhumation.

In recent decades, the dramatic development of stent technologies and popularization of more potent $\mathrm{P} 2 \mathrm{Y} 12$ receptor inhibitors have witnessed a productively decline in the incidence of ischemic complications [3, 4]. And S-DAPT has demonstrated its advantages in decreasing bleeding risk and cardiac mortality compared with long-term DAPT in several RCTs and meta-analyses, though associated with a relatively high probability of ischemia [5-10]. Therefore, current ACC/AHA and ESC guidelines unanimously recommend at least a 6 -month duration of DAPT for patients with stable CAD after DES implantation; furthermore, 3-month DAPT for those with high bleeding risk, and more than 12-month DAPT for patients with the ACS [1, 2]. Paradoxically, a subsequent meta-analysis of 9 randomized trials suggested that 3 or 6 months of DAPT offering non-inferior protection from major cardiovascular 
ischemic events could be safely considered among ACS patients, which highlighted the feasibility of SDAPT in patients enduring higher ischemia hazards [11].

Post-discharge bleeding was confirmed to be a significant contributing factor to cardiac and all-cause mortality, which greater than that associated with post-discharge MI [12]. Therefore, S-DAPT + P2Y12 was proposed lately to balancing thrombotic with hemorrhagic risks and has shown its superiority in several studies [13-17].

Thus, we conducted a network meta-analysis to narrow the gap where finite head-to-head experiment conclusions exist up to now and took full advantage of both direct and indirect evidence to comprehensively evaluate the safety and efficacy of various kinds of DAPT, eventually making recommendations for DAPT among patients after DES implantation.

\section{Methods:}

This network meta-analysis was performed in accordance with the Preferred Reporting Items for Systematic Reviews and Meta-Analysis (PRISMA) guidelines [18].

\section{Search Strategy and Selection Criteria:}

Two investigators (Y.S. and Y.H.) systematically and independently searched five databases (PubMed, Embase, the Cochrane Library, Web of Science, and ClinicalTrials.gov) without language restrictions from their inception to 24 May 2020. The following keywords and controlled vocabularies: platelet aggregation inhibitors, aspirin, drug-eluting stent, percutaneous coronary intervention, randomized controlled trial, were used in different combinations (Additional file 1). The data of the TICO trial has published on 16 June 2020 was added to this study. Presentations about unpublished relevant RCTs of important international conferences were verified simultaneously for additional literature to guarantee a comprehensive search.

Eligible RCTs were supposed to meet the following inclusion criteria: 1) participants were adults with ACD who received DAPT after undergoing PCI with DES implantation; 2) the comparison interventions corresponded with more than two different arms of following candidate durations of DAPT: longer than 12 months (L-DAPT), 12 months (DAPT 12Mo), shorter than 6-month therapy followed by aspirin monotherapy (S-DAPT+ASA), shorter than 6-month therapy followed by a P2Y12 receptor inhibitor monotherapy (S-DAPT+P2Y12); 3) at least one of the following outcomes: all-cause mortality, cardiac death, MI, stroke, major bleeding, any bleeding, definite or probable ST, were accessible; 4) a 12-month follow-up or longer.

Exclusion criteria included the following: 1) non-randomized trials; 2) bare-metal stents (BMSs) were predominantly used in trials; 3 ) uncompleted trials or irretrievable data (both baseline characteristics and outcomes); 4) trials were designed to analyze different kinds of stents, pharmacokinetics, platelet reactivity, or those with a cross-over design. 


\section{Data extraction and quality assessment:}

Two investigators (Y.X. and P.Z.) independently screened the titles, abstracts, and sequentially full articles under the guidance of inclusion criteria and then extracted data on the study design, baseline characteristics, and outcomes from full texts or published appendixes using pre-specified forms. The efficacy endpoints of interest included all-cause mortality, cardiac death, Ml, stroke, major bleeding, any bleeding, definite or probable ST. We gave preference to data from long term or mature follow-up of premier trials. And data extraction was under the instruction of the intention-to-treat principle. We appraised the quality of eligible studies according to the Cochrane Risk of Bias Tool based on six dimensions [19]. Moreover, a third investigator (J.J.) identified the accuracy of the information and handled contradictions by consensus.

\section{Data synthesis and statistical analysis:}

We applied odds ratios (OR) with corresponding 95\% confidence intervals (Cl) to demonstrate time-toevent data quantifying the contributions of each duration, and $95 \% \mathrm{Cl}$ that do not cross one was considered statistically significant. We pooled evidence within the Bayesian framework for its superiority in reconciling complex conditions by using the Aggregate Data Drug Information System (ADDIS version 1.16.8). The network plots were drawn by Stata version 15.1 using the "networkplot" command.

First, we conducted a pair-wise meta-analysis to aggregate data of different treatments in terms of the aforementioned endpoints with a random-effects model (Additional file 2 fig. 1). The heterogeneity of direct comparisons was assessed by the $\mathrm{I}^{2}$ statistic and the $\mathrm{p}$-value [19]. An $\mathrm{I}^{2}$ value of smaller than $25 \%$ indicated low heterogeneity, $25-20 \%$ indicated moderate heterogeneity, above $50 \%$ indicated high heterogeneity, and the larger values represented the higher heterogeneity [19]. The $p$-value of 0.05 was identified as statistical significance [19]. Subsequently, we fitted a Bayesian random-effects network meta-analysis model using Markov chain Monte Carlo (MCMC) algorithms to compare multiple therapies simultaneously. Models were calculated with MCMC simulations, using 4 chains with over-dispersed values, with Gibbs sampling basing on 50,000 simulation iterations after 20,000 tuning iterations. Convergence was assessed by calculating the Potential Scale Reduction Factor (PSRF, the value $<1.2$ was considered as acceptable) according to the Brooks-Gelman-Rubin method [20]. The ranking probabilities of each intervention were calculated, and probabilities were positively related to values. Synthetic outcomes honored consistency when values of inconsistency factors were close to 0 , outcomes of variance calculation were approximately equal, moreover, outcomes of inconsistency and consistency models were equivalent [21]. The node splitting approach was subsequently performed to evaluate consistency [22]. We performed a sensitivity analysis after removing the SMART-DATE trial to confirm the reliability of our outcomes. Besides, pre-specified subgroup analyses were performed for patients with ACS and undergoing newer-generation DES implantation.

\section{Results:}




\section{Search results:}

The systematic search outputted 16,042 citations and 42 articles were subsequently scrutinized. Then, the TICO trial was incorporated. Eventually, 24 randomized controlled trials with aggregately 81,376 participants were deemed eligible for inclusion (Fig. 1) [7-10, 13-17, 23-37].

\section{Characteristics of included studies and bias assessment:}

The fundamental features of enrolled studies, baseline characteristics of participants, definitions of endpoints, outcomes of enrolled trials, and the network plots are summarized in additional file 2.

Generally, 15,158 participants were randomly assigned to the L-DAPT arm, 35,743 to the DAPT 12Mo arm, 14,418 to the S-DAPT+ASA arm, and 16,057 to the S-DAPT+P2Y12 arm. The median follow-up duration was 18 months, with an interquartile range of 12 to 24 months. The distribution of baseline characteristics of patients was balance across comparisons.

An overwhelming majority of RCTs were judged to be low-risk categories according to the Cochrane Risk of Bias Tool, and other sources of bias made a huge contribution to the risk of bias (Additional file 2 table $5)$.

\section{Outcomes of network meta-analysis:}

Fig. 2 gives a representation of network meta-analysis results under the consistency model, and pooled estimates are presented in table 6 in additional file 2.

All-cause mortality and cardiac death:

We synthesized 24 studies reporting all-cause mortality and 21 studies with 60,112 patients altogether reporting cardiac death. Although S-DAPT+P2Y12 resulted in diminished all-cause mortality and cardiac death compared with other DAPT durations, they demonstrated no significant differences (Fig. 2).

Ischemic endpoints:

Overall, L-DAPT had advantages in reducing the probabilities of ischemic complications (Fig. 2). There was a decreasing risk of $\mathrm{Ml}$ in participants treated with L-DAPT compared with S-DAPT+ASA (OR 0.60, 95\% Cl 0.46-0.82) and S-DAPT+P2Y12 (OR 0.69, 95\% Cl 0.44-1.08), but no significant differences were found when compared with S-DAPT+P2Y12. Simultaneously, pooled analysis for definite or probable ST proved to be without statistically significant when L-DAPT compared with S-DAPT+P2Y12 (OR 0.52, $95 \% \mathrm{Cl}$ 0.26-1.10).

Hemorrhagic endpoints:

Results of 18 studies with 54,746 participants about any bleeding and 22 studies with 79,009 participants about major bleeding were pooled. Short term DAPT, especially S-DAPT+P2Y12, was proved to honor overwhelming superiority (Fig. 2). The mate-analysis showed that L-DAPT resulted in an 
increased risk of major bleeding (OR 2.37, 95\% $\mathrm{Cl} 1.32-5.03)$ and any bleeding (OR 2.95, 95\% $\mathrm{Cl} 1.91-4.34)$ when compared with S-DAPT+P2Y12.

Stroke:

A total of 23 studies with 79,896 patients reported the data of stroke. We observed that 4 different therapies presented similar rates, and the differences were not statistically significant among them (Fig. 2).

\section{Rank probabilities:}

The rank probabilities were in accordance with the pooled results quantified by OR ( Fig. 3). SDAPT+P2Y12 was ranked the best therapy for reducing all-cause mortality, cardiac death, major bleeding, and any bleeding. Besides, L-DAPT honored admiration in limiting myocardial infarction and definite or probable ST.

\section{Network coherence:}

The node-splitting analysis confirmed there was no significant difference between direct and indirect effects in closed loops, which verified favorable coherence in all endpoints (Additional file 2 table7).

\section{Sensitivity analysis:}

The SMART-DATE trial which defined duration of long term DAPT as 12-month or longer might weaken the contradistinction among different interventions. We excluded it and redefined long-term arm as received DAPT 18 months or longer. Results of sensitivity analysis did not in contradiction compared with the original meta-analysis but had more prominent differences (Additional file 2 table 8 ). Longer than 18 months of DAPT evaluated in higher rates of major bleeding (OR 2.16, 95\% $\mathrm{Cl} 1.27-4.17$ compared with SDAPT+ASA; OR 2.45, 95\% Cl 1.34-5.58 compared with S-DAPT+P2Y12) and any bleeding (OR 2.37, 95\%Cl 1.66-3.36 compared with S-DAPT+ASA; OR 3.13, 95\% Cl 2.03-4.70 compared with S-DAPT+P2Y12; OR $1.68,95 \% \mathrm{Cl} 1.20-2.21$ compared with DAPT $12 \mathrm{Mo}$ ). The robustness of outcomes could also be confirmed in the pooled analysis of the remaining treatments.

\section{Subgroup analysis:}

We conducted subgroup analyses among patients with ACS for their higher ischemic risks relative to those with stable CAD, and among patients after newer-generation DES implantation owning to its superiority in ischemic outcomes $[38,39]$.

Ten trials reported endpoints of ACS subgroup with a total of 25,189 participants and were included for further synthesis (Additional file 2 table 9) [7, 9, 13, 23, 25, 40-44]. L-DAPT was observed an increased risk of any bleeding when compared with DAPT 12Mo S-DAPT+ASA (OR 2.46, 95\% Cl 1.23-6.76), and SDAPT+P2Y12 (Additional file 2 table 10). 
Table 12 in additional file 2 showed that 18 trials with 58228 patients reported endpoints of newergeneration DES subgroup [7-10, 13-17, 23-27, 30, 32,34,36,45,46]. As for S-DAPT+P2Y12, lower risks of major bleeding (OR 0.60, 95\% $\mathrm{Cl}$ 0.34-0.96 when compared with DAPT 12Mo; OR 0.34, 95\% $\mathrm{Cl} 0.13-0.79$ when compared with L-DAPT), any bleeding, as well as all-cause mortality were confirmed when compared with other strategies (Additional file 2 table 13).

\section{Discussion:}

\section{Summary of evidence:}

We applied a Bayesian network meta-analysis, which included 24 RCTs with 81,376 participants to synthetically evaluate the efficacy and safety of four therapeutic regimens of DAPT in patients undergoing $\mathrm{PCl}$ with DES.

The principal findings were summarized as follows:1) S-DAPT, especially when followed by a P2Y12 receptor inhibitor monotherapy, was associated with a significant reduction in hemorrhagic endpoints, and the discrimination became more remarkable when defined long term arm as received DAPT longer than 18 months. 2) S-DAPT led to increasing rates of MI and definite or probable ST, but no obvious difference was obtained when S-DAPT + P2Y12 compared with L-DAPT or DAPT 12Mo. 3) The four regimens had similar possibilities for all-cause mortality, cardiac death, or stroke overall S-DAPT + P2Y12 was relative optimum. 4) In patients with ACS, L-DAPT was observed a decreased risk of MI, besides short term DAPT was confirmed to has equivalent efficacy and safety to DAPT 12Mo. 5) In terms of newer-generation DES, S-DAPT + P2Y12 was associated with lower risks of major bleeding, any bleeding, and all-cause mortality.

Optimal DAPT is controversial concerning constantly updated DESs, clinical presentations, types of pathological coronary vessels, and constantly advanced antiplatelet drugs. On the strength of observational studies, previous guidelines recommended at least a 12-month duration of DAPT in patients receiving DES. Then, when concerning emerging RCTs that gave admiration to S-DAPT primarily enrolled non-ACS patients and prolonged DAPT proved to associated with lower ischemic complications rate without significant bleeding hazards in studies focusing on patients with increasing ischemia risk, recent guidelines gave weight to S-DAPT for patients at lower ischemic risk [1, 2, 29, 30, 32, 34-37]. Shortly afterward, the DAPT-STEMI trial, the REDUCE trial, and successive meta-analyses proved the validity and feasibility of S-DAPT for those with ACS, which contradicted with the guidelines $[11,22,25$, 47].

Recent studies emphasized the correlation between bleeding events and mortality [12]. Based on the former conclusion, current researches were devoted to exploring the safety and efficacy of S-DAPT + P2Y12 to maximize the benefits in terms of bleeding and ischemia events. The SMART-CHOICE, STOPDAOT-2, GLASSY, and TWILIGHT trials conformably honored S-DAPT + P2Y12 for significant reductions in hemorrhagic endpoints without increasing ischemic harm [14-16, 48]. In line with the 
previous studies, our meta-analysis confirmed that S-DAPT + P2Y12 inhibitor monotherapy dramatically reduced the risk of bleeding events without a significant increase in ischemic complications $[13-16,48]$. And in patients implanted with newer-generation DES, which was much less thrombogenic owing to considerably thinner and more biocompatible struts, S-DAPT + P2Y12 was associated with enlarging benefits according to our subgroup analysis.

Though without statistically significant differences, our outcomes revealed non-inferiority for cardiac death and all-cause mortality of S-DAPT when compared with L-DAPT. The thrombotic benefit of L-DAPT in our study, which may have been neutralized by significant bleeding harm, did not transform into a decline in all-cause or cardiovascular mortality. That is to say, bleeding makes a contribution to mortality risk in patients after $\mathrm{PCl}$, and with suggestions from some studies, the hazard conveys risk comparable to that of an MI during follow-up [12]. It also endorsed the application of S-DAPT from another aspect.

As for patients with ACS, our subgroup analysis further confirmed the safety and efficacy of the use of a P2Y12 inhibitor monotherapy strategy, which was in accordance with the TICO trial [13]. However, although without a statistical difference in terms of the S-DAPT + P2Y12 arm, a decreased risk of MI verified in L-DAPT among ACS patients when compared with shorter-term DAPT was still unignorable. Besides, current study also favoring prolonged DAPT among patients who were at a higher ischemic risk, such as those with ACS, diabetes, and patients with previous stenting $[49,50]$. Taking all these into consideration, this kind of patient was inclined to gain more benefit from prolonged DAPT or potent antiplatelet agents compared with patients with stable ischemic heart disease. Thus, cautious interpretation was still required before applying S-DAPT + P2Y12 to patients confronting high ischemic risk in the absence of clinical data.

Our study is the most comprehensive network meta-analysis up to now. We committed to evaluating the efficacy and safety of P2Y12 monotherapy after S-DAPT, which was a newer regimen under exploration. With a combination of direct and indirect comparisons, subsequently, on account of bleeding and ischemic risks, our study makes recommendations for patients with individualized DAPT. Our results suggest that S-DAPT especially continuing P2Y12 monotherapy, admires a lower rate of bleeding events under any clinical presentations. S-DAPT + P2Y12 is safe compared with L-DAPT without significant ischemic harm for patients with ACS after DES implantation. Furthermore, S-DAPT + P2Y12 presents superiority compared with other therapies in patients with all clinical presentations, and in patients with ACS or at high ischemic risk L-DAPT is more admirable than DAPT 12Mo. More broadly, our findings highlight the superiority of P2Y12 monotherapy after short-term DAPT in the precision medical practice and lay the foundation for further research between aspirin monotherapy and P2Y12 monotherapy.

\section{Limitations:}

Our study suffers from several limitations. First, a large majority of eligible RCTs pooled in our metaanalysis precluded patients related to recurrent ischemia and bleeding events; clopidogrel was predominantly used in enrolled trials, which weaken the universality of our conclusion. Second, a majority 
of trials were designed to test the non-inferiority of different DAPT strategies. Third, heterogeneity could be witnessed among the enrolled trials in terms of design and endpoints definitions. Forth, results for ACS patients relied on subgroup or post hoc analyses of original RCTs, so the results should apply modestly in these patients. Finally, the comparison between S-DAPT + ASA and S-DAPT + P2Y12 was merely based on indirect evidence, so the conclusions must be considered exploratory on account of limited statistical power and should be interpreted with caution.

\section{Conclusion:}

S-DAPT associated with reduced risk of bleeding without a significant increase in ischemic complications showed non-inferiority compared with other therapies for patients undergoing PCI. In population with ACS or high risk of ischemic, L-DAPT is still honored. Further pre-specified randomized controlled trials comparing S-DAPT followed by P2Y12 monotherapy with aspirin monotherapy should be conducted to promote the individualization of DAPT.

\section{Abbreviations}

ACC: American College of Cardiology

ACS: Acute coronary syndrome

ADDIS: Aggregate Data Drug Information System

AHA: American Heart Association

BMS: Bare-metal stent

CAD: Coronary artery disease

Cl: Confidence interval

DAPT: Dual antiplatelet therapy

DAPT-STEMI: Six months versus 12 months dual antiplatelet therapy after drug-eluting stent implantation in ST-elevation myocardial infarction (DAPT-STEMI): randomised, multicentre, non-inferiority trial

DAPT 12Mo: 12-months dual antiplatelet therapy

DES: Drug Eluting Stent

ESC: European Society of Cardiology

L-DAPT: Long-term dual antiplatelet therapy

MCMC: Markov chain Monte Carlo 
Ml: Myocardial infarction

OR: Odds ratio

PCl: Percutaneous coronary intervention

PRISMA: Preferred Reporting Items for Systematic Reviews and Meta-Analyses

PSRF: The Potential Scale Reduction Factor

RCT: Randomized controlled trial

REDUCE: Final results of the randomised evaluation of short-term dual antiplatelet therapy in patients with acute coronary syndrome treated with a new-generation stent

S-DAPT: Short-term dual antiplatelet therapy

S-DAPT+ASA: Short-term dual antiplatelet therapy followed by aspirin monotherapy

S-DAPT+P2Y12: Short-term dual antiplatelet therapy followed by a P2Y12 receptor inhibitor monotherapy

SMART-CHOICE: Smart Angioplasty Research Team: Comparison Between P2Y12 Antagonist

Monotherapy vs Dual Antiplatelet Therapy in Patients Undergoing Implantation of Coronary Drug-Eluting Stents

SMART-DATE: 6-month versus 12-month or longer dual antiplatelet therapy after percutaneous coronary intervention in patients with acute coronary syndrome (SMART-DATE): a randomised, open-label, noninferiority trial

ST: Stent thrombosis

STOPDAPT-2: Short and Optimal Duration of Dual Antiplatelet Therapy After Everolimus- Eluting CobaltChromium Stent

TICO: Effect of Ticagrelor Monotherapy vs Ticagrelor With Aspirin on Major Bleeding and Cardiovascular Events in Patients With Acute Coronary Syndrome: The TICO Randomized Clinical Trial

TWILIGHT: Ticagrelor with Aspirin or Alone in High-Risk Patients after Coronary Intervention

\section{Declarations}

Ethics approval and consent to participate: Not applicable.

Consent for publication: Not applicable. 
Availability of data and materials: The datasets used and/or analysed during the current study are available from the corresponding author on reasonable request.

Competing interests: The authors declare that they have no competing interests.

Funding: None.

Authors' contributions: All authors contributed to the study conception and design. Y.S. and Y.H. searched the literature. Y.X. and P.Z. extracted the data. Y.X. and Y.S. analyzed data. Y.X. and P.Z written the first draft of this manuscript. J.J contributed to the revision of manuscript. All authors read and approved the final manuscript.

Acknowledgements: Not applicable.

Authors' information: 1.Department of Cardiology, The Second Affiliated Hospital of Zhejiang University School of Medicine, 88 Jiefang Road, Hangzhou, Zhejiang 310009, China; 2.School of Chinese Materia Medica, Nanjing University of Chinese Medicine, 138 Xianlin Avenue, Nanjing 210023, China; 3.State Key Laboratory of Drug Research, Shanghai Institute of Materia Medica, Chinese Academy of Sciences, 501 Haike Road, Shanghai 201203, China; 4.Department of pharmacy, ChinacoHealthcare Corporation International Hospital, 599 Shiji Road, Ningbo, Zhejiang 315315, China

\section{References}

1. Levine GN, Bates ER, Bittl JA, Brindis RG, Fihn SD, Fleisher LA, et al 2016 ACC/AHA Guideline Focused Update on Duration of Dual Antiplatelet Therapy in Patients With Coronary Artery Disease: A Report of the American College of Cardiology/American Heart Association Task Force on Clinical Practice Guidelines: An Update of the 2011 ACCF/AHA/SCAI Guideline for Percutaneous Coronary Intervention, 2011 ACCF/AHA Guideline for Coronary Artery Bypass Graft Surgery, 2012 ACC/AHA/ACP/AATS/PCNA/SCAI/STS Guideline for the Diagnosis and Management of Patients With Stable Ischemic Heart Disease, 2013 ACCF/AHA Guideline for the Management of ST-Elevation Myocardial Infarction, 2014 AHA/ACC Guideline for the Management of Patients With Non-STElevation Acute Coronary Syndromes, and 2014 ACC/AHA Guideline on Perioperative Cardiovascular Evaluation and Management of Patients Undergoing Noncardiac Surgery. Circulation. 2016;134:e123-e55.

2. Valgimigli M, Bueno H, Byrne RA, Collet J-P, Costa F, Jeppsson A, et al. 2017 ESC focused update on dual antiplatelet therapy in coronary artery disease developed in collaboration with EACTS: The Task Force for dual antiplatelet therapy in coronary artery disease of the European Society of Cardiology (ESC) and of the European Association for Cardio-Thoracic Surgery (EACTS). Eur Heart J. 2017;39:213-60.

3. Räber L, Magro M, Fau - Stefanini GG, Stefanini Gg Fau -. Kalesan B, Kalesan B, Fau - van Domburg RT, van Domburg Rt Fau -. Onuma Y, Onuma Y, Fau - Wenaweser P, et al. Very late coronary stent 
thrombosis of a newer-generation everolimus-eluting stent compared with early-generation drugeluting stents: a prospective cohort study. Circulation. 2012;125(9):1110-21.

4. Furtado RHM, Nicolau JC, Magnani G, Im K, Bhatt DL, Storey RF, et al. Long-term ticagrelor for secondary prevention in patients with prior myocardial infarction and no history of coronary stenting: insights from PEGASUS-TIMI 54. Eur Heart J. 2020;41(17):1625-32.

5. Palmerini T, Benedetto U, Bacchi-Reggiani L, Riva DD, Biondi-Zoccai G, Feres F, et al. Mortality in patients treated with extended duration dual antiplatelet therapy after drug-eluting stent implantation: a pairwise and Bayesian network meta-analysis of randomised trials. The Lancet. 2015;385:2371-82.

6. Sharma A, Agrawal S, Garg A, Vallakati A, Lavie CJ, Helft G. Duration of dual antiplatelet therapy following drug-eluting stent implantation: A systemic review and meta-analysis of randomized controlled trials with longer follow up. Catheter Cardiovasc Interv. 2017;90:31-7.

7. Hahn J-Y, Bin Song Y, Oh J-H, Cho D-K, Lee JB, Doh J-H, et al. 6-month versus 12-month or longer dual antiplatelet therapy after percutaneous coronary intervention in patients with acute coronary syndrome (SMART-DATE): a randomised, open-label, non-inferiority trial. Lancet. 2018;391:1274-84.

8. Nakamura M, lijima R, Ako J, Shinke T, Okada H, Ito Y, et al. Dual Antiplatelet Therapy for 6 Versus 18 Months After Biodegradable Polymer Drug-Eluting Stent Implantation. Jacc-Cardiovascular Interventions. 2017;10:1189-98.

9. Didier R, Morice MC, Barragan P, Noryani AAL, Noor HA, Majwal T, et al. 6-Versus 24-Month Dual Antiplatelet Therapy After Implantation of Drug-Eluting Stents in Patients Nonresistant to Aspirin Final Results of the ITALIC Trial (Is There a Life for DES After Discontinuation of Clopidogrel). JaccCardiovascular Interventions. 2017;10:1202-10.

10. Valgimigli M, Campo G, Monti M, Vranckx P, Percoco G, Tumscitz C, et al. Short-versus long-term duration of dual-antiplatelet therapy after coronary stenting: A randomized multicenter trial. Circulation. 2012;125:2015-26.

11. Verdoia M, Kedhi E, Suryapranata H, Frati G, Biondi-Zoccai G, De Luca G. Benefits of short-term or prolonged as compared to standard 1 year DAPT in patients with acute coronary syndrome treated with drug-eluting stents: a meta-analysis of 9 randomized trials. J Thromb Thrombolysis. 2020;50:337-54.

12. Généreux P, Giustino G, Witzenbichler B, Weisz G, Stuckey TD, Rinaldi MJ, et al. Incidence, Predictors, and Impact of Post-Discharge Bleeding After Percutaneous Coronary Intervention. J Am Coll Cardiol. 2015;66(9):1036-45.

13. Kim BK, Hong SJ, Cho YH, Yun KH, Kim YH, Suh Y, et al. Effect of Ticagrelor Monotherapy vs Ticagrelor With Aspirin on Major Bleeding and Cardiovascular Events in Patients With Acute Coronary Syndrome: The TICO Randomized Clinical Trial. Jama. 2020;323:2407-16.

14. Watanabe H, Domei T, Morimoto T, Natsuaki M, Shiomi H, Toyota T, et al. Effect of 1-Month Dual Antiplatelet Therapy Followed by Clopidogrel vs 12-Month Dual Antiplatelet Therapy on 
Cardiovascular and Bleeding Events in Patients Receiving PCl: The STOPDAPT-2 Randomized Clinical Trial. JAMA - Journal of the American Medical Association. 2019;321:2414-27.

15. Mehran R, Baber U, Sharma SK, Cohen DJ, Angiolillo DJ, Briguori C, et al. Ticagrelor with or without aspirin in high-risk patients after PCI. N Engl J Med. 2019;381:2032-42.

16. Hahn JY, Song YB, Oh JH, Chun WJ, Park YH, Jang WJ, et al. Effect of P2Y12 Inhibitor Monotherapy vs Dual Antiplatelet Therapy on Cardiovascular Events in Patients Undergoing Percutaneous Coronary Intervention: the SMART-CHOICE Randomized Clinical Trial. JAMA. 2019;321:2428-37.

17. Vranckx P, Valgimigli M, Jüni P, Hamm C, Steg PG, Heg D, et al. Ticagrelor plus aspirin for 1 month, followed by ticagrelor monotherapy for 23 months vs aspirin plus clopidogrel or ticagrelor for 12 months, followed by aspirin monotherapy for 12 months after implantation of a drug-eluting stent: a multicentre, open-label, randomised superiority trial. The Lancet. 2018;392:940-9.

18. Moher D, Liberati A, Tetzlaff J, Altman DG. Preferred reporting items for systematic reviews and meta-analyses: The PRISMA statement. Int J Surg. 2010;8:336-41.

19. Higgins JPT, Thomas J, Chandler J, Cumpston M, Li T, Page MJ, et al. Cochrane Handbook for Systematic Reviews of Interventions version 6.0 (updated July 2019). Cochrane, 2019. http://www.training.cochrane.org/handbook.

20. Brooks SP, Gelman A. General methods for monitoring convergence of iterative simulations. Journal of Computational Graphical Statistics. 1998;7:434-55.

21. Dias S, Welton NJ, Sutton AJ, Caldwell DM, Lu G, Ades AE. NICE DSU technical support document 4: inconsistency in networks of evidence based on randomised controlled trials. 2011; updated April 2014. NICE Decision Support Unit, 2014. http://nicedsu.org.uk/.

22. van Valkenhoef G, Dias S, Ades AE, Welton NJ. Automated generation of node-splitting models for assessment of inconsistency in network meta-analysis. Res Synth Methods. 2016;7:80-93.

23. De Luca G, Damen SA, Camaro C, Benit E, Verdoia M, Rasoul S, et al. Final results of the randomised evaluation of short-term dual antiplatelet therapy in patients with acute coronary syndrome treated with a new-generation stent (REDUCE trial). Eurolntervention. 2019;15:e990-e8.

24. Lee BK, Kim JS, Lee OH, Min PK, Yoon YW, Hong BK, et al. Safety of six-month dual antiplatelet therapy after secondgeneration drug-eluting stent implantation: OPTIMA-C randomised clinical trial and OCT substudy. Eurolntervention. 2018;13:1923-30.

25. Kedhi E, Fabris E, van der Ent M, Buszman P, von Birgelen C, Roolvink V, et al. Six months versus 12 months dual antiplatelet therapy after drug-eluting stent implantation in ST-elevation myocardial infarction (DAPT-STEMI): randomised, multicentre, non-inferiority trial. BMJ. 2018;363:k3793.

26. Hong S-J, Shin D-H, Kim J-S, Kim B-K, Ko Y-G, Choi D, et al. 6-Month Versus 12-Month DualAntiplatelet Therapy Following Long Everolimus-Eluting Stent Implantation The IVUS-XPL Randomized Clinical Trial. Jacc-Cardiovascular Interventions. 2016;9:1438-46.

27. Han Y, Xu B, Xu K, Guan C, Jing Q, Zheng Q, et al. Six Versus 12 Months of Dual Antiplatelet Therapy After Implantation of Biodegradable Polymer Sirolimus-Eluting Stent: randomized Substudy of the ILOVE-IT 2 Trial. Circulation Cardiovascular interventions. 2016;9:e003145. 
28. Helft G, Steg PG, Le Feuvre C, Georges JL, Carrie D, Dreyfus X, et al. Stopping or continuing clopidogrel 12 months after drug-eluting stent placement: The OPTIDUAL randomized trial. Eur Heart J. 2015;37:365-74.

29. Schulz-Schüpke S, Byrne RA, Ten Berg JM, Neumann FJ, Han Y, Adriaenssens T, et al. ISAR-SAFE: A randomized, double-blind, placebo-controlled trial of 6 vs. 12 months of clopidogrel therapy after drug-eluting stenting. Eur Heart J. 2015;36:1252-63.

30. Mauri L, Kereiakes DJ, Yeh RW, Driscoll-Shempp P, Cutlip DE, Steg PG, et al. Twelve or 30 months of dual antiplatelet therapy after drug-eluting stents. N Engl J Med. 2014;371:2155-66.

31. Lee CW, Ahn JM, Park DW, Kang SJ, Lee SW, Kim YH, et al. Optimal duration of dual antiplatelet therapy after drug-eluting stent implantation: a randomized, controlled trial. Circulation. 2014;129:304-12.

32. Colombo A, Chieffo A, Frasheri A, Garbo R, Masotti-Centol M, Salvatella N, et al. Second-Generation Drug-Eluting Stent Implantation Followed by 6-Versus 12-Month Dual Antiplatelet Therapy The SECURITY Randomized Clinical Trial. J Am Coll Cardiol. 2014;64:2086-97.

33. Collet JP, Silvain J, Barthélémy O, Rangé G, Cayla G, Van Belle E, et al. Dual-antiplatelet treatment beyond 1 year after drug-eluting stent implantation (ARCTIC-Interruption): a randomised trial. Lancet. 2014;384:1577-85.

34. Feres F, Costa RA, Abizaid A, Leon MB, Marin-Neto JA, Botelho RV, et al. Three vs Twelve Months of Dual Antiplatelet Therapy After Zotarolimus-Eluting Stents The OPTIMIZE Randomized Trial. JamaJournal of the American Medical Association. 2013;310:2510-22.

35. Kim BK, Hong MK, Shin DH, Nam CM, Kim JS, Ko YG, et al. A new strategy for discontinuation of dual antiplatelet therapy: The reset trial (real safety and efficacy of 3-month dual antiplatelet therapy following endeavor zotarolimus-eluting stent implantation). J Am Coll Cardiol. 2012;60:1340-8.

36. Gwon HC, Hahn JY, Park KW, Song YB, Chae IH, Lim DS, et al. Six-month versus 12-month dual antiplatelet therapy after implantation of drug-eluting stents: The efficacy of xience/promus versus cypher to reduce late loss after stenting (EXCELLENT) randomized, multicenter study. Circulation. 2012;125:505-13.

37. Park SJ, Park DW, Kim YH, Kang SJ, Lee SW, Lee CW, et al. Duration of dual antiplatelet therapy after implantation of drug-eluting stents. N Engl J Med. 2010;362:1374-82.

38. Loh JP, Pendyala LK, Kitabata H, Torguson R, Omar A, Minha S, et al. Comparison of outcomes after percutaneous coronary intervention among different coronary subsets (stable and unstable angina pectoris and ST-segment and non-ST-segment myocardial infarction). Am J Cardiol. 2014;113:1794801.

39. Kang SH, Chae IH, Park JJ, Lee HS, Kang DY, Hwang SS, et al. Stent Thrombosis With Drug-Eluting Stents and Bioresorbable Scaffolds: Evidence From a Network Meta-Analysis of 147 Trials. JACC Cardiovasc Interv. 2016;9:1203-12.

40. Costa F, Vranckx P, Leonardi S, Moscarella E, Ando G, Calabro P, et al. Impact of clinical presentation on ischaemic and bleeding outcomes in patients receiving 6- or 24-month duration of dual- 
antiplatelet therapy after stent implantation: a pre-specified analysis from the PRODIGY (Prolonging Dual-Antiplatelet Treatment After Grading Stent-Induced Intimal Hyperplasia) trial. Eur Heart J. 2015;36:1242-51.

41. Yeh RW, Kereiakes DJ, Steg PG, Windecker S, Rinaldi MJ, Gershlick AH, et al. Benefits and Risks of Extended Duration Dual Antiplatelet Therapy After PCl in Patients With and Without Acute Myocardial Infarction. J Am Coll Cardiol. 2015;65:2211-21.

42. Lohaus R, Michel J, Mayer K, Lahmann AL, Byrne RA, Wolk A, et al. Six Versus Twelve Months Clopidogrel Therapy After Drug-Eluting Stenting in Patients With Acute Coronary Syndrome: An ISARSAFE Study Subgroup Analysis. Sci Rep. 2016;6:33054.

43. Jang JY, Shin DH, Kim JS, Hong SJ, Ahn CM, Kim BK, et al. Optimal duration of DAPT after secondgeneration drug-eluting stent in acute coronary syndrome. PLoS One. 2018;13:e0207386.

44. Tomaniak M, Chichareon P, Onuma Y, Deliargyris EN, Takahashi K, Kogame N, et al. Benefit and Risks of Aspirin in Addition to Ticagrelor in Acute Coronary Syndromes: A Post Hoc Analysis of the Randomized GLOBAL LEADERS Trial. JAMA Cardiol. 2019;4:1092-101.

45. Hermiller JB, Krucoff MW, Kereiakes DJ, Windecker S, Steg PG, Yeh RW, et al. Benefits and Risks of Extended Dual Antiplatelet Therapy After Everolimus-Eluting Stents. JACC Cardiovasc Interv. 2016;9:138-47.

46. Valgimigli M, Borghesi M, Tebaldi M, Vranckx P, Parrinello G, Ferrari R. Should duration of dual antiplatelet therapy depend on the type and/or potency of implanted stent? A pre-specified analysis from the PROlonging Dual antiplatelet treatment after Grading stent-induced Intimal hyperplasia studY (PRODIGY). Eur Heart J. 2013;34:909-19.

47. Yin SH, Xu P, Wang B, Lu Y, Wu QY, Zhou ML, et al. Duration of dual antiplatelet therapy after percutaneous coronary intervention with drug-eluting stent: systematic review and network metaanalysis. Bmj. 2019;365:I2222.

48. Franzone A, McFadden E, Leonardi S, Piccolo R, Vranckx P, Serruys PW, et al. Ticagrelor Alone Versus Dual Antiplatelet Therapy From 1 Month After Drug-Eluting Coronary Stenting. J Am Coll Cardiol. 2019;74:2223-34.

49. Rath $D$, Geisler T. Optimal antiplatelet and anticoagulation strategies in acute coronary syndromes. Herz. 2020;45:528-36.

50. Bhatt DL, Steg PG, Mehta SR, Leiter LA, Simon T, Fox K, et al. Ticagrelor in patients with diabetes and stable coronary artery disease with a history of previous percutaneous coronary intervention (THEMIS-PCI): a phase 3, placebo-controlled, randomised trial. Lancet. 2019;394:1169-80.

\section{Figures}


All records identified through database searching $(\mathrm{N}=15714)$

Pubmed 2363

Embase $\quad \mathbf{8 2 3 1}$

Cochrane Library $\quad 3497$

Web of Science 1623
Records identified form trial register searching $(\mathrm{N}=328)$

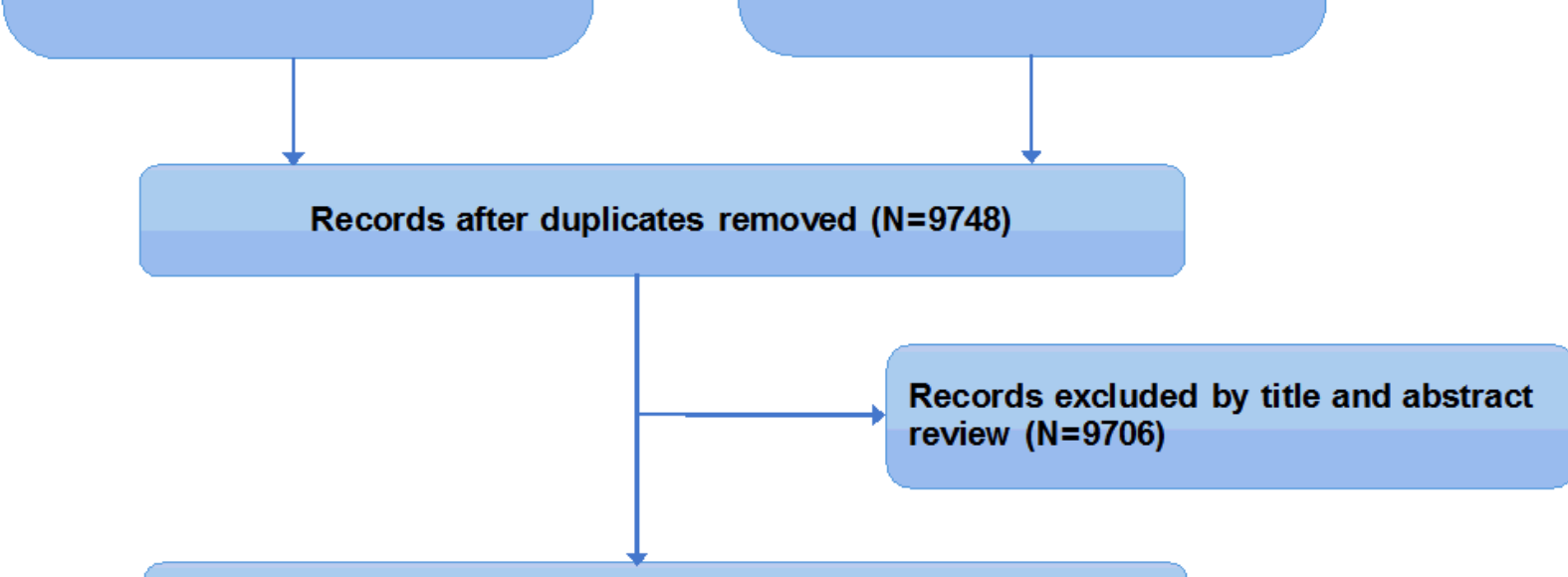

Full articles assessed for eligibility $(\mathrm{N}=42)$

TICO trial was additionally included( $\mathrm{N}=1)$

\section{Figure 1}

PRISMA flow diagram detailing study selection 
L-DAPT vs. DAPT 12Mo

All cause mortality

Cardiac death

Myocardial Infarction

Stroke

Major bleeding

Any bleeding

Definte or probable stent thrombosis

L-DAPT vs. S-DAPT+ASA

All cause mortality

Cardiac death

Myocardial Infarction

Stroke

Major bleeding

Any bleeding

Definte or probable stent thrombosis

L-DAPT vs. S-DAPT+P2Y12

All cause mortality

Cardiac death

Myocardial Infarction

Stroke

Major bleeding

Any bleeding

Definte or probable stent thrombosis

DAPT 12Mo vs. S-DAPT+ASA

Al cause mortality

Cardiac death

Myocardial Infarction

Stroke

Maior bleeding

Any bleeding

Definte or probable stent thrombosis

DAPT 12Mo vs. S-DAPT+P2Y12

All cause mortality

Cardiac death

Myocardial Infarction

Stroke

Major bleeding

Any bleeding

Definte or probable stent thrombosis

S-DAPT+ASA vs. S-DAPT+P2Y12

All cause mortality

Cardiac death

Myocardial Infarction

Stroke

Major bleeding

Any bleeding

Definte or probable stent thrombosis

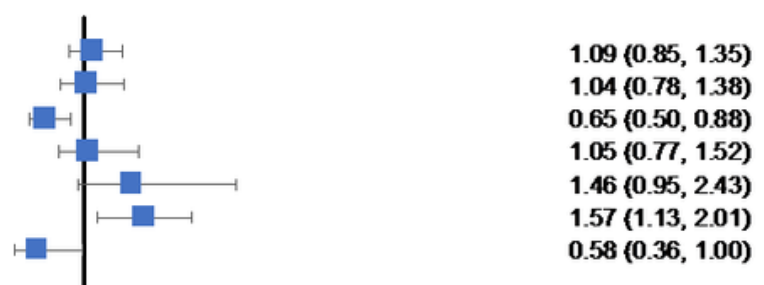

$1.15(0.91,1.47)$

$1.08(0.81,1.47)$

$0.60(0.46,0.82)$

$1.11(0.76,1.62)$

$2.05(1.26,3.70)$

$2.11(1.55,2.87)$

$0.51(0.31,0.87)$

$1.22(0.86,1.67)$

$1.46(0.88,2.32)$

$0.69(0.44,1.08)$

$1.03(0.64,1.70)$

$2.37(1.32,5.03)$

$2.95(1.91,4.34)$

$0.52(0.26,1.10)$

$1.06(0.85,1.36)$

$1.04(0.78,1.41)$

$0.92(0.72,1.15)$

$1.04(0.72,1.49)$

$1.40(0.92,226)$

$1.35(1.08,1.80)$

$0.89(0.57,1.33)$

$1.12(0.88,1.43)$

$1.41(0.93,2.05)$

$1.06(0.83,1.42)$

$0.98(0.68,1.37)$

$1.62(1.07,2.73)$

$1.88(1.41,2.61)$

$0.92(0.50,1.52)$

$1.06(0.74,1.45)$

$1.34(0.81,2.12)$

$1.15(0.83,1.72)$

$0.93(0.57,1.54)$

$1.16(0.61,2.25)$

$1.39(0.92,2.02)$

$1.03(0.51,2.03)$

\section{Figure 2}

Forest plots illustrating network meta-analysis results of all endpoints 

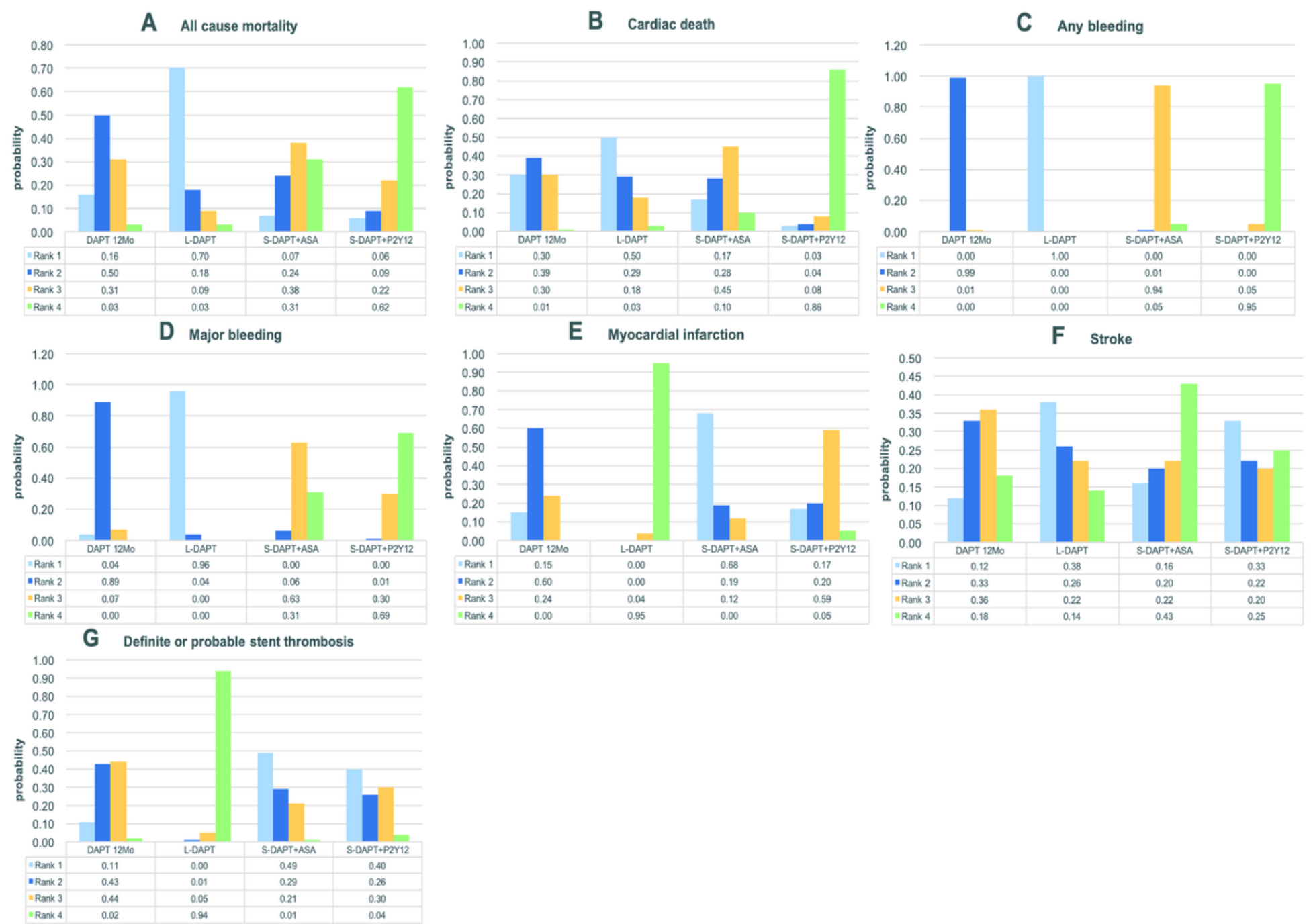

\section{Figure 3}

Rankograms demonstrating the probability of each therapy ranked at each endpoint (rank 1 is worst and rank 4 is best)

\section{Supplementary Files}

This is a list of supplementary files associated with this preprint. Click to download.

- PRISMAchecklist.doc

- Additionalfile2.docx

- Additionalfile1.docx 